\title{
Formation of nano-sized oxides in the K-Ta-O system by chemical reaction of Ta metal with $\mathrm{KNO}_{3}-\mathrm{KOH}$ melts
}

\author{
Irene V. KOVALENKO ${ }^{1}$, Liudmyla V. CHERNENKO ${ }^{1}$, Sergei A. KHAINAKOV ${ }^{2}$, Alexander A. ANDRIIKO ${ }^{1}$, \\ Vladimir I. LISIN ${ }^{3}$ \\ ${ }^{1}$ Chair of General and Inorganic Chemistry, Faculty of Chemical Technology, National Technical University \\ of Ukraine "KPI", Prospekt Peremogy 37, 03056 Kyiv, Ukraine \\ 2 Department of Organic and Inorganic Chemistry, University of Oviedo, 33006 Oviedo, Spain \\ ${ }^{3}$ Faculty of Chemical Technology, Kyiv National University of Technology and Design, \\ Nemirovicha-Danchenko St. 2, 01011 Kyiv, Ukraine \\ * Corresponding author.Tel.: +380-44-4549883; e-mail: andriiko@xtf.ntu-kpi.kiev.ua
}

Received September 18, 2008; accepted November 27, 2008; available on-line March 19, 2009

The reaction of Ta metal with potassium nitrate melts at $600^{\circ} \mathrm{C}$ has been studied. It was established that the composition of the reaction product could be varied by an appropriate choice of the base-acid properties of the melt, which were regulated by additions of potassium hydroxide. Pure potassium metatantalate $\mathrm{KTaO}_{3}$ is formed when the $\mathrm{KOH} / \mathrm{KNO}_{3}$ molar ratio is about 1.2 or slightly higher. A mixture of the metatantalate with tetra- and ditantalate $\left(\mathrm{K}_{2} \mathrm{Ta}_{4} \mathrm{O}_{11}\right.$ and $\left.\mathrm{K}_{2} \mathrm{Ta}_{2} \mathrm{O}_{6}\right)$ is formed at lower molar ratios. The content of tetratantalate increases as the concentration of $\mathrm{KOH}$ in the melt decreases and it becomes the main reaction product in pure nitrate melt. Pure metatantalate was obtained in the form of powders with grain sizes of about $80 \mathrm{~nm}$. This product possessed ferroelectric properties with a dielectric constant of 250-300. Such nano-powders exhibit the properties of a semiconductor, which is not common for large-crystal materials. The conductivity is $10^{-5} \mathrm{~S} \mathrm{~cm}^{-1}$ at room temperature and increases exponentially with increasing temperature.

Potassium tantalates / Nitrate melts / Nano-sized oxides / Metatantalate / Ferroelectricity

Introduction

Several potassium tantalates(V) are known with different $\mathrm{K}_{2} \mathrm{O} / \mathrm{Ta}_{2} \mathrm{O}_{5}$ ratios from polytantalates $\mathrm{K}_{2} \mathrm{O} \cdot \mathrm{nTa}_{2} \mathrm{O}_{5} \quad(\mathrm{n} \geq 2)$ to orthotantalate $\mathrm{K}_{3} \mathrm{TaO}_{4} \quad[1,2]$. Among them, metatantalate $\mathrm{KTaO}_{3}$ with perovskite structure is possibly the most practically important one in view of its ferroelectric properties [3].

Commonly, ceramic methods are used for the synthesis of crystalline $\mathrm{KTaO}_{3}$. They are based on the calcination of a mixture of $\mathrm{Ta}_{2} \mathrm{O}_{5}$ with potassium hydroxide or carbonate at $1200-2000^{\circ} \mathrm{C}$. According to the phase diagram of the system $\mathrm{K}_{2} \mathrm{O}-\mathrm{Ta}_{2} \mathrm{O}_{5}$ [4], metatantalate melts incongruently at $1370^{\circ} \mathrm{C}$. Hence, it is not surprising that the ceramic method does not allow producing high-purity monophase crystals of metatantalate. Besides, this method is energy consuming and technically complicated, requiring high-temperature corrosion resistant equipment.

Sol-gel synthesis is under investigation as an alternative to the ceramic one. Tantalum and potassium alcoholates are most often used as precursors in this method [5-7]. Sol-gel synthesis is commonly used for the preparation of thin films of potassium tantalate or its solid solutions. For the same purpose, laser spray deposition has been proposed. In particular, it has been used to prepare highly oriented films of metatantalate on silicon single crystals [8].

Recently, the method of preparation of various metal oxides, both simple and complex ones, by oxidation of metals or their compounds in molten nitrate media has received considerable attention [9-11]. The main advantage of this method is the by far lower formation temperatures of the oxides (300$500^{\circ} \mathrm{C}$ ), which simplifies the process and decreases the energy consumption. In addition, the method enables preparation of nanoscale oxide materials, which are now a subject of worldwide investigation because of a number of unique properties distinguishing them from the common large-crystal materials [12,13]. Finally, the method makes it possible to vary the composition of the product, changing the basicity by means of additives to the melt.

In the present work, we have studied the formation of different tantalates by oxidation of tantalum metal 
powder in a potassium nitrate melt, the basicity of which was varied by potassium hydroxide additives.

\section{Experimental}

Tantalum powder (assay 99.9\%, particle size $5-10 \mu \mathrm{m})$ and chemical grade potassium nitrate and hydroxide were used. The oxidation process was carried out in air at $500-600^{\circ} \mathrm{C}$ in alumina crucibles placed in an electric furnace. At the end of the reaction (1-1.5 hours), the melt was cooled down to room temperature and rinsed with distilled water. A milkwhite suspension was formed, which was centrifuged to separate the fine powder of the product. The powder was washed, first with water, then with ethanol, and dried in air at $100-110^{\circ} \mathrm{C}$.

The phase composition of the product was investigated by XRD with a DRON-3M diffractometer and $\mathrm{CuK}_{\alpha}$ radiation. For measuring the electric properties, the powder was pressed into cylindrical tablets of 4-7 mm length and $5 \mathrm{~mm}$ diameter. To produce the tablets, the powder was mixed with a $5 \%$ aqueous solution of polyvinyl alcohol up to the formation of a viscous mass, which was then pressed at $400 \mathrm{~kg} \mathrm{~cm}^{-2}$, dried in air at room temperature and then at $700{ }^{\circ} \mathrm{C}$.

The dielectric constant of the samples was measured with a digital RCL-meter E7-8 at room temperature with $1 \mathrm{kHz}$ working frequency. The electrical conductivity of the pressed tablets was determined in the temperature range $20-100^{\circ} \mathrm{C}$ with an $\mathrm{AC}$ bridge at frequencies from 0.1 to $10 \mathrm{kHz}$. Electron microscopy investigations were performed by the TEM method with a MET JEOL-2000 EX-II microscope operating at $200 \mathrm{kV}$.

\section{Results and discussion}

A general simplified scheme for the oxidation of tantalum metal can be conveniently represented as the combination of the 5-electron half-reaction of oxidation followed by the acid-base equilibrium of the formation of tantalates:

$\mathrm{Ta} \Leftrightarrow \mathrm{Ta}^{5+}+5 \mathrm{e}^{-}$,

$n \mathrm{Ta}^{5+}+m \mathrm{O}^{2-} \Leftrightarrow \mathrm{Ta}_{n} \mathrm{O}_{m}{ }^{5 n-2 m}$,

where the $m / n$ ratio, depending on the acid-base properties of the molten media, can vary from 2.5 $\left(\mathrm{Ta}_{2} \mathrm{O}_{5}\right.$ oxide $)$ to $4\left(\mathrm{~K}_{3} \mathrm{TaO}_{4}\right.$ orthotantalate $)$ via intermediate values $2.5<\mathrm{m} / \mathrm{n}<3$ for polytantalates and 3 for metatantalate. The electrons from Ta (reaction 1) are consumed in the half-reaction of the nitrate ion reduction, which can proceed in different ways, also depending on the basicity of the melt:

$\mathrm{NO}_{3}^{-}+2 \mathrm{e}^{-} \Leftrightarrow \mathrm{NO}_{2}^{-}+\mathrm{O}^{2-}$

or

$\mathrm{NO}_{3}{ }^{-}+\mathrm{e}^{-} \Leftrightarrow \mathrm{NO}_{2}+\mathrm{O}^{2-}$

Hence, one can conclude that the acid-base properties of the media is a key factor determining the path of the metal oxidation reaction and thus the possibility to produce the required product.

According to the Lux-Flood theory, in melts containing oxoanions, an acceptor of oxygen ions $\mathrm{O}^{2-}$ is an acid and its donor is a base [14,15]. The acidbase equilibrium (2) is a particular case of a general equation, which can be represented as:

$\mathrm{Me}^{\mathrm{z}+}$ (acid) $+n \mathrm{O}^{2-} \Leftrightarrow \mathrm{MeO}_{n}{ }^{\mathrm{z}-2 \mathrm{n}}$ (base)

The nitrate ion itself is considered as a base dissociating in accordance with the reaction [16]: $\mathrm{NO}_{3}{ }^{-} \Leftrightarrow \mathrm{NO}_{2}^{+}+\mathrm{O}^{2-}$

Introducing some acid species (e.g. metal cations) into the melt shifts the equilibrium (6) to the right, very reactive cations $\mathrm{NO}_{2}^{+}$accumulate in the melt and decomposition occurs according to the equation:

$\mathrm{NO}_{2}^{+}+\mathrm{NO}_{3}^{-} \Leftrightarrow 2 \mathrm{NO}_{2}+1 / 2 \mathrm{O}_{2}$

Since the quantitative characteristics of the acidbase equilibria in molten nitrates are not known, we cannot envisage beforehand the required composition (basicity) of the reaction mixture, which is necessary to form, for instance, pure $\mathrm{KTaO}_{3}$. It seems probable that the content of $\mathrm{O}^{2-}$ in pure molten potassium nitrate should not be enough to form this phase. The experiment confirms this assumption. The XRD pattern of the product obtained by oxidation of $\mathrm{Ta}$ powder in pure molten $\mathrm{KNO}_{3}$, with its molar ratio to Ta being equal to 5 , at $650^{\circ} \mathrm{C}$ (Fig.1, pattern 1) shows the tetratantalate $\mathrm{K}_{2} \mathrm{Ta}_{4} \mathrm{O}_{11}$ (JCPDS 12-0092) as the main phase with small admixtures of $\delta-\mathrm{Ta}_{2} \mathrm{O}_{5}$ (JCPDS 18-1304), ditantalate $\mathrm{K}_{2} \mathrm{Ta}_{2} \mathrm{O}_{6}$ (JCPDS 21-0685), and metatantalate $\mathrm{KTaO}_{3}$ (JCPDS 2-0822).

As follows from the above, it is necessary to increase the basicity of the melt by adding donors of oxygen ions to obtain the required phase of metatantalate. The most convenient substance for this purpose is potassium hydroxide. According to the Lux-Flood concept, its basicity is provided by the equilibrium:

$2 \mathrm{OH}^{-} \Leftrightarrow \mathrm{H}_{2} \mathrm{O}+\mathrm{O}^{2-}$

That is why we have studied the oxidation of $\mathrm{Ta}$ in $\mathrm{KNO}_{3}-\mathrm{KOH}$ melts with different content of potassium hydroxide. The ratio $\mathrm{KNO}_{3} / \mathrm{Ta}=5$ was fixed and the KOH/Ta ratio was varied. Fig. 1 (patterns 2-4) and Fig. 2 show the results of this study. One can see that the increase of the basicity ( $\mathrm{KOH}$ to $\mathrm{Ti}$ ratio with fixed amount of $\mathrm{KNO}_{3}$ ) results in the gradual increase of the content of metatantalate in the samples. Finally, it becomes the only product of the $\mathrm{Ta}$ oxidation at $\mathrm{KOH} / \mathrm{Ta}=1.2$. In that case, the overall reaction for the synthesis of $\mathrm{KTaO}_{3}$ can be written as follows:

$2 \mathrm{KOH}+2 \mathrm{Ta}+5 \mathrm{KNO}_{3} \rightarrow 2 \mathrm{KTaO}_{3}+5 \mathrm{KNO}_{2}+\mathrm{H}_{2} \mathrm{O}$

As follows from (9), the experimental composition that we have found for the synthesis of pure metatantalate corresponds to a $20 \%$ excess of $\mathrm{KOH}$ $(\mathrm{KOH} / \mathrm{Ta}=1.2)$ and $100 \%$ excess of $\mathrm{KNO}_{3}$ $\left(\mathrm{KNO}_{3} / \mathrm{Ta}=5\right)$.

Pure cubic phase of $\mathrm{KTaO}_{3}$ with cell parameter $a=3.988 \AA$ was obtained at these conditions (Fig. 1, pattern 4$)$. 


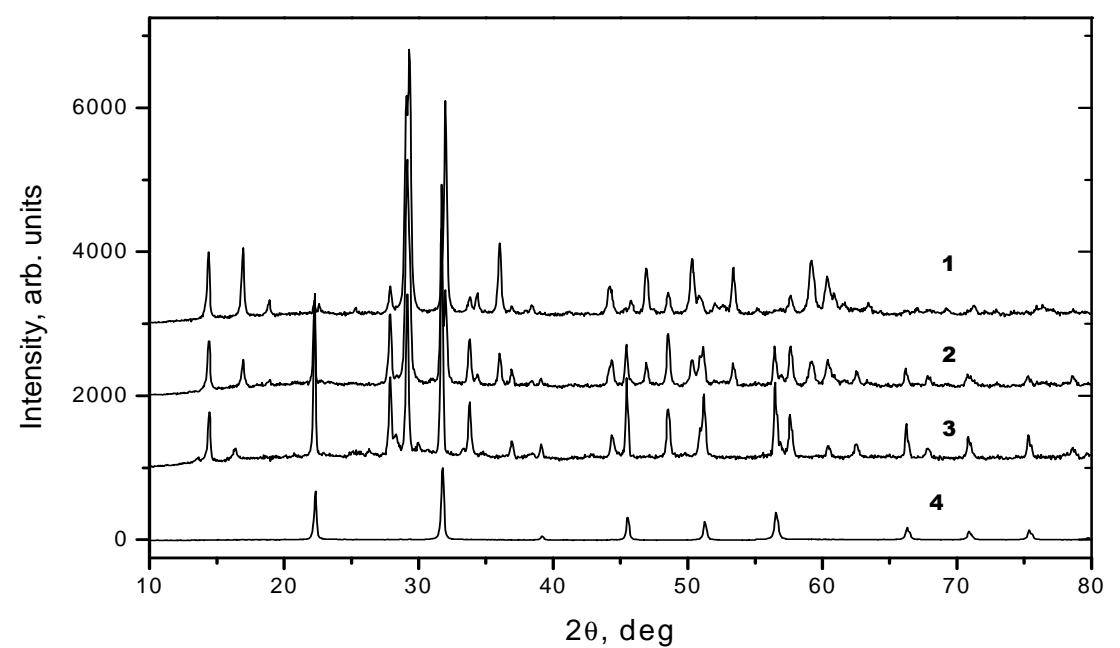

Fig. 1 XRD patterns of samples obtained by oxidation of Ta powder at $650{ }^{\circ} \mathrm{C}$ in molten $\mathrm{KNO}_{3}$ for the molar ratios $\mathrm{KNO}_{3} / \mathrm{Ta}=5$ and $\mathrm{KOH} / \mathrm{Ta}=0$ (pattern 1), $0.3(2), 1$ (3) or 1.2 (4).

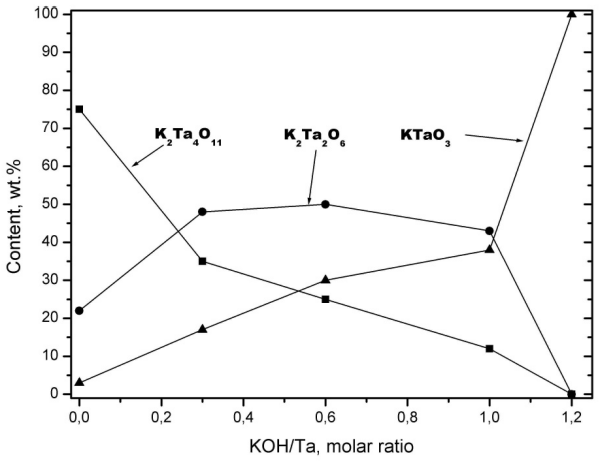

Fig. 2 Approximate phase compositions of samples obtained by oxidation of Ta powder at $650{ }^{\circ} \mathrm{C}$ for a fixed molar ratio $\mathrm{KNO}_{3} / \mathrm{Ta}=5$, varying the $\mathrm{KOH} / \mathrm{Ta}$ ratio. The contents were estimated from the relative intensities of appropriate XRD peaks.

The sizes of the crystals were estimated from XRD data using the Debye-Scherrer equation:

$d=\frac{0.9 \lambda}{B \cos \Theta}$

where $\lambda=0.1542 \mathrm{~nm}$ is the wavelength of the X-ray radiation, $B$ is the half-width of the diffraction maximum in radians, $\Theta$ is the angle corresponding to the position of the diffraction maximum. The average crystal size for the sample of Fig. 2 is equal to 90-95 nm, which agrees with the data of the TEM investigation (Fig. 3). Such a product should be related to the class of nanomaterials. However, it is known that the special features of nanoscale materials become most pronounced for crystal sizes of about $10-50 \mathrm{~nm}$ [13]. That is why we have studied the possibility to decrease the size of the crystals by means of dilution of the melt, i.e. by increasing the amount of liquid phase in the reaction mixture with respect to the solid Ta powder, keeping the $\mathrm{KOH}$ to Ta ratio fixed. A set of experiments was carried out where the molar compositions of the reaction mixtures were $\mathrm{Ta} / \mathrm{KOH} / \mathrm{KNO}_{3}=1 / 1.2 / m(m=5,10,15,10$, $25)$. The obtained samples were investigated by XRD, the lattice constants and average crystal sizes were determined and dielectric constants measured. The results are presented in Fig. 3 and Table 1.

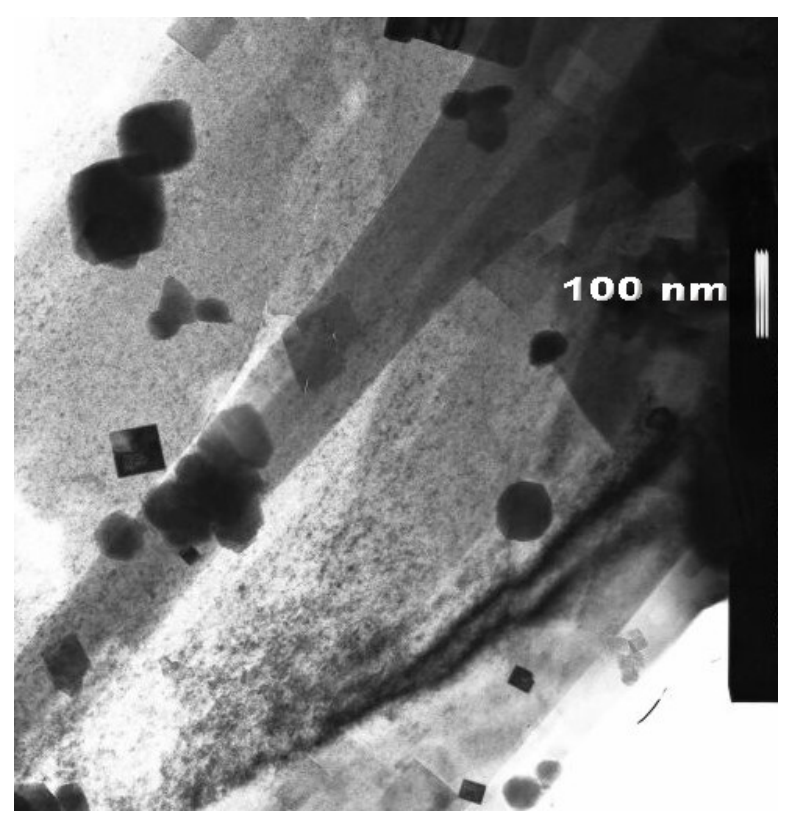

Fig. 3 TEM image of the powder of potassium metatantalate. Well formed cubic crystals with dimensions not exceeding $100 \mathrm{~nm}$ are clearly seen. 
Table 1 Some properties of metatantalate samples prepared by oxidation of Ta powder at $650^{\circ} \mathrm{C}$ with different content of potassium nitrate and constant ratio $\mathrm{KOH} / \mathrm{Ta}=1.2$ in the reaction mixtures.

\begin{tabular}{c|c|c|c|c}
\hline $\begin{array}{c}\text { Sample } \\
\#\end{array}$ & $\begin{array}{c}\mathrm{KNO}_{3}: \mathrm{Ta} \\
\text { molar ratio }\end{array}$ & $\begin{array}{c}\text { Lattice parameter } \\
\text { Average crystal dimension }\end{array}$ & Dielectric constant $^{\mathrm{b}}$ \\
\hline 1 & 5 & 3.9886 & $\mathrm{D}, \mathrm{nm}$ & $\mathcal{E}$ \\
2 & 10 & 3.9829 & 86 & 262 \\
3 & 15 & 3.9857 & 85 & 243 \\
4 & 20 & 3.9864 & 85 & 293 \\
$5^{\mathrm{c}}$ & 25 & 3.9889 & 85 & 225 \\
\hline
\end{tabular}

${ }^{a}$ calculated by the Debye-Scherrer equation (10)

$\mathrm{b}$ average from two independently measured values

${ }^{c}$ this sample contains small admixtures of polytantalates

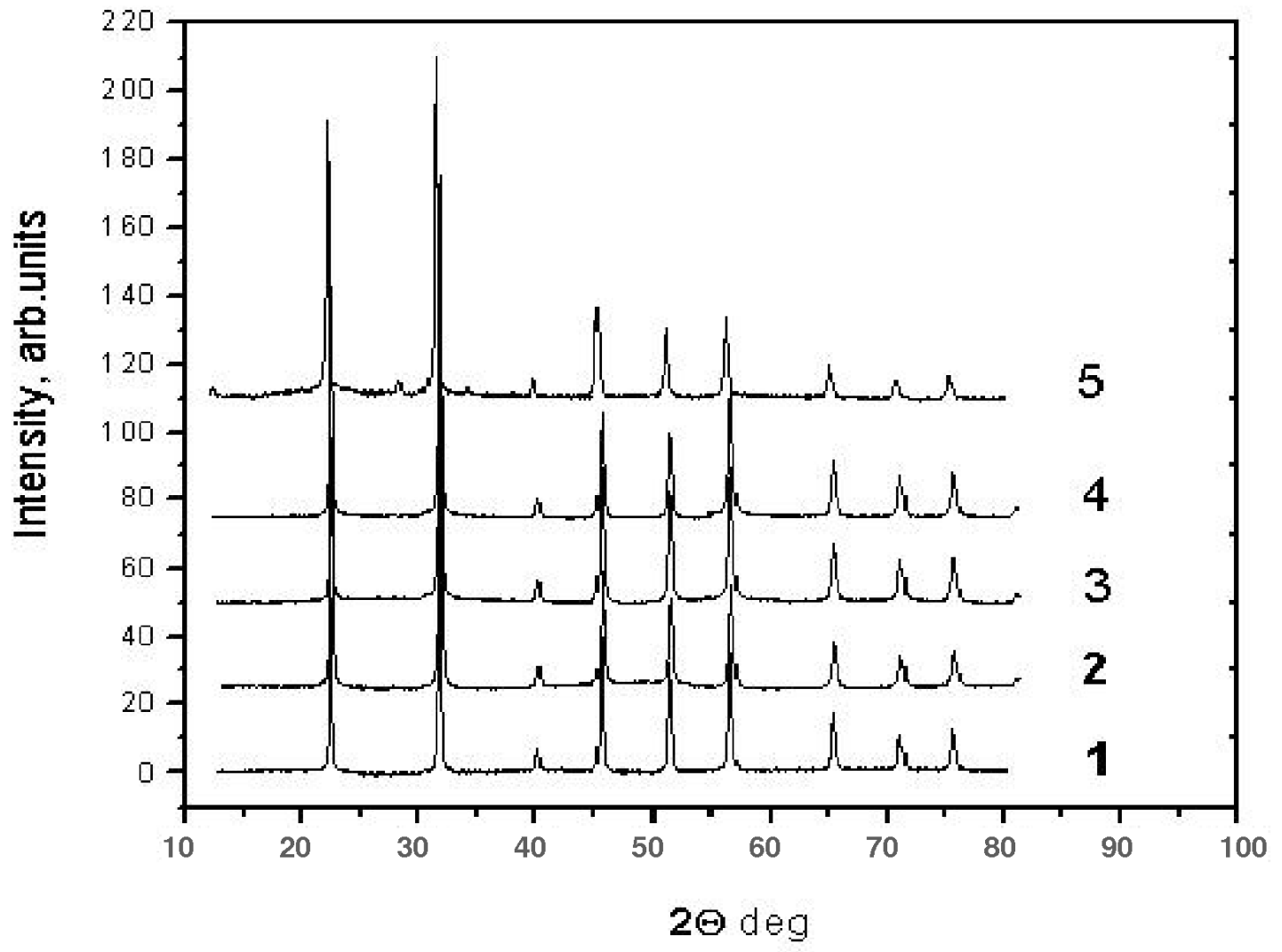

Fig. 4 XRD patterns of samples obtained by oxidation of Ta powder in molten $\mathrm{KNO}_{3}$ at $650^{\circ} \mathrm{C}$ for the molar ratios $\mathrm{KOH} / \mathrm{Ta}=1.2$ and $\mathrm{KNO}_{3} / \mathrm{Ta}=5$ (pattern 1), 10 (2), 15 (3), 20 (4), or 25 (5).

As follows from the data of Table 1, an increase of the relative amount of the nitrate results first in a slight decrease of the average crystal size, and then, for $\mathrm{KNO}_{3} / \mathrm{Ta}>10$, causes practically no effect. The basicity of the melt becomes insufficient at very high dilutions (sample 5) and the product contains small admixtures of polytantalates. That is the possible reason for the somewhat lower dielectric constant of this sample. Thus, an increase of the nitrate content beyond $\mathrm{KNO}_{3} / \mathrm{Ta}=10$ is not recommended since it increases the consumption of chemical with no essential effect on the properties of the product.

Though the results confirmed the ferroelectric properties of the product, the reproducibility of the independent determinations of the dielectric constant was rather poor - the values for different tablets from the same material varied in the range of 40-50 units. The insufficient quality of the pressed pellets could be one of the reasons - we failed to attain a porosity less than $50 \%$. However, the main reason is the electric conductivity of this material, which was found to be about $10^{-5} \mathrm{~S} \mathrm{~cm}^{-1}$ at room temperature, increasing exponentially with increasing temperature (Fig. 5). Such a temperature dependence of the conductivity points to semiconductor properties with a width of the forbidden zone of about $0.3 \mathrm{eV}$, as can be estimated from the experimental value of the activation energy $\mathrm{E}_{\mathrm{A}}=28.9 \pm 0.1 \mathrm{~kJ}$. To our knowledge, such properties 
are not common for large crystals of $\mathrm{KTaO}_{3}$ prepared by ceramic technique. Probably, it is the nanosize of the crystals that is responsible for such behavior.

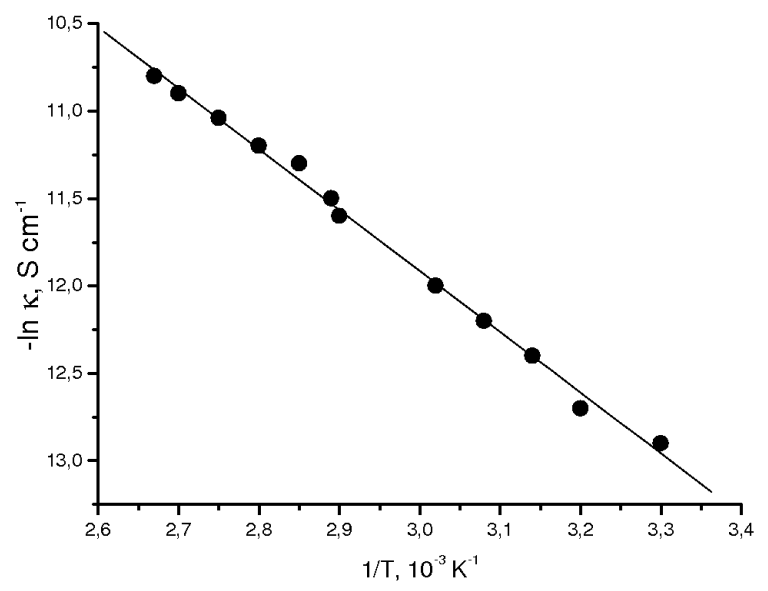

Fig. 5 Temperature dependence of the specific conductivity (sample \#3 of Table 1) in form of an Arrhenius plot.

\section{Conclusions}

Pure potassium metatantalate can be prepared by oxidation of tantalum metal powder in potassium nitrate melt with additions of potassium hydroxide. The synthesis temperature is $600-650{ }^{\circ} \mathrm{C}$, which is more than twice lower than required by common ceramic methods.

The recommended composition of the chemicals is rendered by the molar relation $\mathrm{Ta} / \mathrm{KOH} / \mathrm{KNO}_{3} \approx$ 1/(1.2-1.3)/(5-10). Perovskite-structured $\quad \mathrm{KTaO}_{3}$ without any impurities of poly- or orthotantalates is formed under these conditions. Amounts of polytantalates are formed at lower contents of $\mathrm{KOH}$ in the reaction mixture.

The metatantalate is a ferroelectric with a dielectric constant higher than 250. The crystal size of the product was about $80-90 \mathrm{~nm}$, which permits to relate it to the type of nanoscale materials. This material behaves as a semiconductor with noticeable conductivity $\left(10^{-6}-10^{-5} \mathrm{~S} \mathrm{~cm}^{-1}\right)$, which is not observed for the large-crystal material.

\section{Acknowledgements}

The authors acknowledge partial financial support of the Ukrainian Ministry for Education and Science, project 2991F. S.A. Khainakov gratefully acknowledges the support of the Spanish Ministerio de Educación y Ciencia (PCI2005-A7-0110, MAT2006-01997).

\section{References}

[1] Ya.G. Goroshchenko, Chemistry of Tantalum and Niobium, Naukova Dumka, Kiev, 1965, p. 326 (in Russian).

[2] F. Fairbrother, Chemistry of Niobium and Tantalum, Mir, Moscow, 1972, p. 275 (in Russian).

[3] G.A. Smolenskiy, N.I. Krainik, Ferroelectrics and Antiferroelectrics, Khimiya, Moscow, 1968, 262 p. (in Russian).

[4] A. Reisman, F. Holtzberg, M. Berkenblit, M. Berry, J. Am. Chem. Soc. 78 (1956) 4514.

[5] S. Hirano, T. Yogo, K. Kikuta, T. Morishita, Y. Ito, J. Am. Ceram. Soc. 75 (1992) 1701.

[6] C.J. Lu, A.X. Kuang, J. Mater. Sci. 32(16) (1997) 4421.

[7] G. Garnweitner, M. Niederberger, J. Am. Ceram. Soc. 89 (2006) 1801.

[8] W.D. Ma, Z.S. Zhao, S.M. Wang, D.M. D.D. Zhang, Xu, X.D. Wang, Z.J. Chen, Phys. Status Solidi A 176 (1999) 985.

[9] C. Matei, P. Marote, B. Durand, J.P. Deloume, I. Jitaru, Proc. Int. Symp. Ionic Liquids in Honor of Marcelle Gaune-Escard, Carry le Rouet, France, 2003, pp. 325-332.

[10] S.V. Volkov, S.M. Maliovanyi, E.V. Panov, Russ. J. Inorg. Chem. 47 (2002) 1749.

[11] R. Lionet, C. Ciravino, P. Marote, J.P. Scharf, B. Durand, J.P. Deloume, In: M. Gaune-Escard, (Ed.), Advances in Molten Salts: from Structural Aspects to Waste Processing, Proc. Eur. Res. Conf. Molten Salts, Porquerolles Island, France, 1998, pp. 169-180.

[12] H. Gleiter, Nanostruct. Mater. 1 (1992) 1-35.

[13] K.J. Klabunde (Ed.), Nanoscale Materials in Chemistry, Wiley, NJ, 2001, 292 p.

[14] H. Lux, Z. Elektrochem. 45 (1939) 303.

[15] H. Flood, T. Förland, Acta Chem. Scand. 1 (1947) 592.

[16] D.H. Kerridge, In: J.J. Lagovski (Ed.), The Chemistry of Nonaqueous Solvents, Academic Press, New York, 1978, Vol. VB, p. 269. 